\title{
Hypermethylation of the $\kappa 1$ opioid receptor promoter in Chinese heroin and methamphetamine addicts
}

\author{
HUIHUI JI $^{1 *}$, GUILI LIU $^{1 *}$, XUTING XU ${ }^{1 *}$, HUIFEN LIU ${ }^{2}$, LEI XU ${ }^{1}$, HAOCHANG HU ${ }^{1}$, \\ YINGMIN CHEN $^{1}$, QINXIAO HONG ${ }^{2}$, QINWEN WANG ${ }^{1}$, WENWEN SHEN ${ }^{2}$, \\ LONGHUI $\mathrm{LI}^{2}$, XIAOHU XIE ${ }^{2}$, WENHUA ZHOU ${ }^{2}$ and SHIWEI DUAN ${ }^{1}$ \\ ${ }^{1}$ Medical Genetics Center, School of Medicine, Ningbo University, Ningbo, Zhejiang 315211; \\ ${ }^{2}$ Laboratory of Behavioral Neuroscience, Ningbo Addiction Research and Treatment Center, \\ Ningbo, Zhejiang 315010 , P.R. China
}

Received October 25, 2016; Accepted April 11, 2017

DOI: $10.3892 /$ etm.2018.6514

\begin{abstract}
Heroin and methamphetamine (METH) addiction continues to be a major social, economic and therapeutic problem worldwide. The opioid pathway may mediate the effects of addictive drugs. However, the potential correlation between the $\kappa 1$ opioid receptor (OPRK1) and drug addiction has not yet been characterized. The aim of the present study was to investigate the potential association between methylation of the OPRK1 promoter and substance abuse. Bisulfite pyrosequencing technology was used to determine the levels of OPRK1 promoter methylation in 60 drug abusers (30 heroin and 30 METH addicts) and 52 controls, observed to exhibit no significant differences in age or gender. The results indicated that levels of OPRK1 promoter methylation were significantly higher in drug addicts when compared with controls $\left(\mathrm{P}=2.43 \times 10^{-4}\right)$. Significant correlations between OPRK1 promoter methylation and the length and frequency of drug use were also observed in male heroin addicts (length: $\mathrm{r}=0.661, \mathrm{P}=0.007$; frequency: $\mathrm{r}=-0.684, \mathrm{P}=0.005$ ). In addition, a luciferase reporter gene assay indicated that the OPRK1 promoter fragment was able to regulate gene expression (fold change between two groups $>32.12, \mathrm{P} \leq 0.0001$ ). In conclusion, results of the present study indicate that methylation of the
\end{abstract}

Correspondence to: Dr Shiwei Duan, Medical Genetics Center, School of Medicine, Ningbo University, Wangchanglai Building, 818 Fenghua Road, Jiangbei, Ningbo, Zhejiang 315211, P.R. China

E-mail: duanshiwei@nbu.edu.cn

Dr Wenhua Zhou, Laboratory of Behavioral Neuroscience, Ningbo Addiction Research and Treatment Center, 42 Xibei Road, Haishu, Ningbo, Zhejiang 315010, P.R. China

E-mail:whzhou@vip.163.com

*Contributed equally

Key words: $\kappa 1$ opioid receptor, promoter, methylation, heroin, methamphetamine, addiction
OPRK1 promoter contributes to the pathophysiology of drug addiction.

\section{Introduction}

Drug addiction is a costly and disabling condition, which arises from the combined effects of genetic and environmental interactions. Addicts are characterized by uncontrollable drug-taking and drug-seeking behaviors, and have a high likelihood of relapse for an extensive period after the cessation of drug use (1). The number of heroin addicts worldwide has been increasing substantially, and the rate of heroin users aged $>12$ years increased from $0.16 \%$ between 2002 and 2004 to $0.26 \%$ between 2011 and 2013 in the United States (2). Recently, there has been a marked increase in the use of a novel drug in China, termed methamphetamine (METH), and at the end of 2012, there were $\sim 0.41$ million registered METH addicts nationwide, accounting for $23 \%$ of all drug addicts (3). The rate of METH use is second only to the rate of heroin use (3). Both heroin and METH addictions may cause a number of social problems, including the spread of human immunodeficiency virus (4).

Opioid receptors are important in the development and maintenance of addiction, dysphoria and reward mechanisms in the brain (5). Increased methylation of the $\mu 1$ opioid receptor promoter has been identified in the lymphocytes of former heroin users on methadone maintenance (6). OPRK1 encodes the $\kappa 1$ opioid receptor, which is a member of the opioid family. Genetic polymorphisms in OPRK1 have been associated with alcohol dependence $(7,8)$, body weight and opioid withdrawal symptoms (8).

Epigenetics is defined as the investigation of heritable changes in gene transcription and phenotypic alterations that are independent of DNA sequence changes (9). DNA methylation is among the most commonly studied epigenetic mechanisms (10), and is typically represented by covalent modifications at the 5-position of cytosine to form 5-methylcytosine (11-13). More recently, several studies have indicated an epigenetic role in molecular processes in the brain such as the protein kinase A CREB pathway and calcium-dependent phosphorylation cascades, which may lead to an addiction 
to psychostimulants (14-18). In addition, a previous study demonstrated that methylation of brain-derived neurotrophic factor was correlated with heroin and METH addiction (19), suggesting that the blockade of drug effects on epigenetic markers may be useful in the treatment of drug addiction. The aim of the present study was to investigate the potential association between OPRK1 promoter methylation and drug addiction.

\section{Materials and methods}

Subjects and clinical data. A total of 60 drug users including 30 heroin (mean age, 30.90 \pm 0.97 years; 50:50 males:females) and 30 METH addicts (mean age, 31.03 $\pm 0.99 ; 50: 50$ males:females) were recruited from the Ningbo Addiction Research and Treatment Center (Ningbo, China) from June 2012 to June 2013. The control group consisted of 52 individuals that exhibited no significant differences in age or gender (mean age, 30.90 \pm 0.73 years; 27:25 males:females), who were recruited from Ningbo Blood Bank. Patients with drug addictions were diagnosed according to the diagnostic and statistical manual of mental disorders, fourth edition (DSM-IV) (20). Individuals who had a history of psychiatric disease, severe disease, aged $<18$ years or $>65$ years were excluded. All controls were free from any nervous system diseases and had no history of drug addiction. In addition, the Profile of Mood State (POMS) interview records of male patients were collected. The present study was approved by the Ethics Committees of Ningbo University (Ningbo, China) and Ningbo Addiction Research and Treatment Center, and written informed consent was obtained from all participants.

DNA methylation assay. DNA extraction and quality tests were performed as described previously (21). The level of DNA methylation was measured using bisulfite pyrosequencing technology which combined sodium bisulfite DNA conversion chemistry (EZ DNA Methylation-Gold ${ }^{\mathrm{TM}}$ kit), polymerase chain reaction (PCR) amplification $\left(\mathrm{Zymo} \mathrm{Taq}^{\mathrm{TM}}\right.$ PCR PreMix; both from Zymo Research Corporation, Irvine, CA, USA) and sequencing by synthesis assay (Pyromark Gold Q24 Reagents; Qiagen, Hilden, Germany) as previously described (22). A fragment containing $7 \mathrm{CpG}$ sites from $O P R K 1$ promoter was used to represent the DNA methylation of $O P R K 1$ promoter. Primers for PCR were designed PyroMark Assay Design software, version 2.0 as described previously (Qiagen) (23). Each PCR reaction consisted of $10 \mu 1$ 2xPCR PreMix $\left(Z y m o\right.$ Taq $^{\mathrm{TM}}$ PCR PreMix), $0.5 \mu 1$ forward primer $(10 \mu \mathrm{M}), 0.5 \mu 1$ reversed primer $(10 \mu \mathrm{M}), 1 \mu \mathrm{l}$ template DNA, and $8 \mu \mathrm{l}$ water. PCR was completed as follows, for 45 cycles; $95^{\circ} \mathrm{C}$ for $30 \mathrm{sec}, 58^{\circ} \mathrm{C}$ for $40 \mathrm{sec}$ and $72^{\circ} \mathrm{C}$ for $50 \mathrm{sec}$, followed by $72^{\circ} \mathrm{C}$ for $7 \mathrm{~min}$. The sequences used for target gene (OPRK1) amplification were 5'-biotin-TTAGTATTTAAGAGGAAAAGGGAAAGT TGT-3' for the forward primer and 5'-CCCCCATCATAACTA AAAATCT-3' for the reverse primer, and 5'-GGGAAAGTT GTTGGG-3' for the sequencing primer for pyrosequencing. The methylation level was obtained directly via PyroMark Assay Design software 2.0.

Construction of recombinant plasmids. One long fragment (OPRK1 L) and one short fragment (OPRK1 S) from the OPRK1 promoter region were selected for a luciferase reporter gene assay (24). The OPRK1 L fragment contained the pyrosequenced sequence, while the OPRK1 S fragment did not. The following primers were used to amplify OPRK1 L: Forward, 5'-CGGGGTACCGGCCGGTGC CTAGAATT-3' and reverse, 5'-CTAGCTAGCGCCTGA CCCTCACTCCCT-3'. The following primers were used to amplify OPRK1 S: Forward, 5'-CGGGGTACCGGC CGGTGCCTAGAATT-3' and reverse, 5'-CTAGCTAGC CAAGCCCACGACGAACAC-3'. The PCR reaction was performed using Taq DNA Polymerase TQ2100 (Omega Bio-Tek, Inc., Norcross, GA, USA) according to manufacturer's instructions. PCR conditions used were as follows: $95^{\circ} \mathrm{C}$ for $10 \mathrm{~min}$ and then 35 cycles of $98^{\circ} \mathrm{C}$ for $10 \mathrm{sec}$, $65^{\circ} \mathrm{C}$ for $15 \mathrm{sec}$ and $72^{\circ} \mathrm{C}$ for $1 \mathrm{~min}$; followed by a further 10 min extension at $72^{\circ} \mathrm{C}$. The pGL3-Basic vector (Promega Corporation, Madison, WI, USA) lacked the eukaryotic promoter and enhancer sequence that allowed maximum flexibility in cloning putative regulatory sequences. A gel extraction kit (Omega Bio-Tek, Inc.) was used to gel purify the PCR products according to the manufacturer's protocol, which were subsequently quantified using a Nanodrop 2000 spectrophotometer (Thermo Fisher Scientific, Inc., Waltham, MA, USA). Then the purified PCR products were digested with NheI (5'-G^CTAGC-3') and Kpn1 (5'-GGTAC^C-3'; New England Biolabs, Inc., Ipswich, MA, USA) and cloned into a pGL3-Basic vector, which had $l u c^{+}$gene using a DNA ligation kit (Takara Bio, Inc., Otsu, Japan) following the manufacturer's protocol. The total volume for each double digestion reaction was $50 \mu \mathrm{l}$ including $5 \mu \mathrm{l}$ buffer, $1 \mu \mathrm{l}$ NheI (20,000 U/ml), $1 \mu \mathrm{l} \mathrm{Kpn1} \mathrm{(20,000} \mathrm{U/ml),} 30 \mu \mathrm{l}$ PCR product or $5 \mu \mathrm{l}$ pGL3 plasmid DNA (as the control) and water up to $50 \mu \mathrm{l}$. The double digestion was performed in $37^{\circ} \mathrm{C}$ water bath for $15 \mathrm{~min}$. All the primers were synthesized by Sangon Biotech Co., Ltd. (Shanghai, China).

Luciferase reporter gene assay. Human HEK293T cells (American Type Culture Collection, Manassas, VA, USA) were transfected with recombinant plasmids and used in the luciferase reporter gene assay. The protocol was performed as described previously (25).

Statistical analysis. Statistical analysis was performed using PASW statistics 18.0 software (SPSS, Inc., Chicago, IL, USA). The data were presented as mean \pm standard deviation. The mean values of two groups were compared using a Student's t-test. The Pearson's correlation test was used to determine potential associations between OPRK1 promoter methylation and the length and frequency of drug use in male patients. $\mathrm{P}<0.05$ was considered to indicate a statistically significant difference.

\section{Results}

Association of 7 CpG sites. A fragment from the OPRK1 promoter containing seven 5'-C-phosphate-G-3' (CpG) sites was bisulphite pyrosequenced to detect the level of OPRK1 promoter methylation, as depicted in Fig. 1. Within these seven sites, methylation of a given site was significantly correlated with methylation of any other site $(r>0.50, \mathrm{P}<0.05$; Fig. 1$)$. 


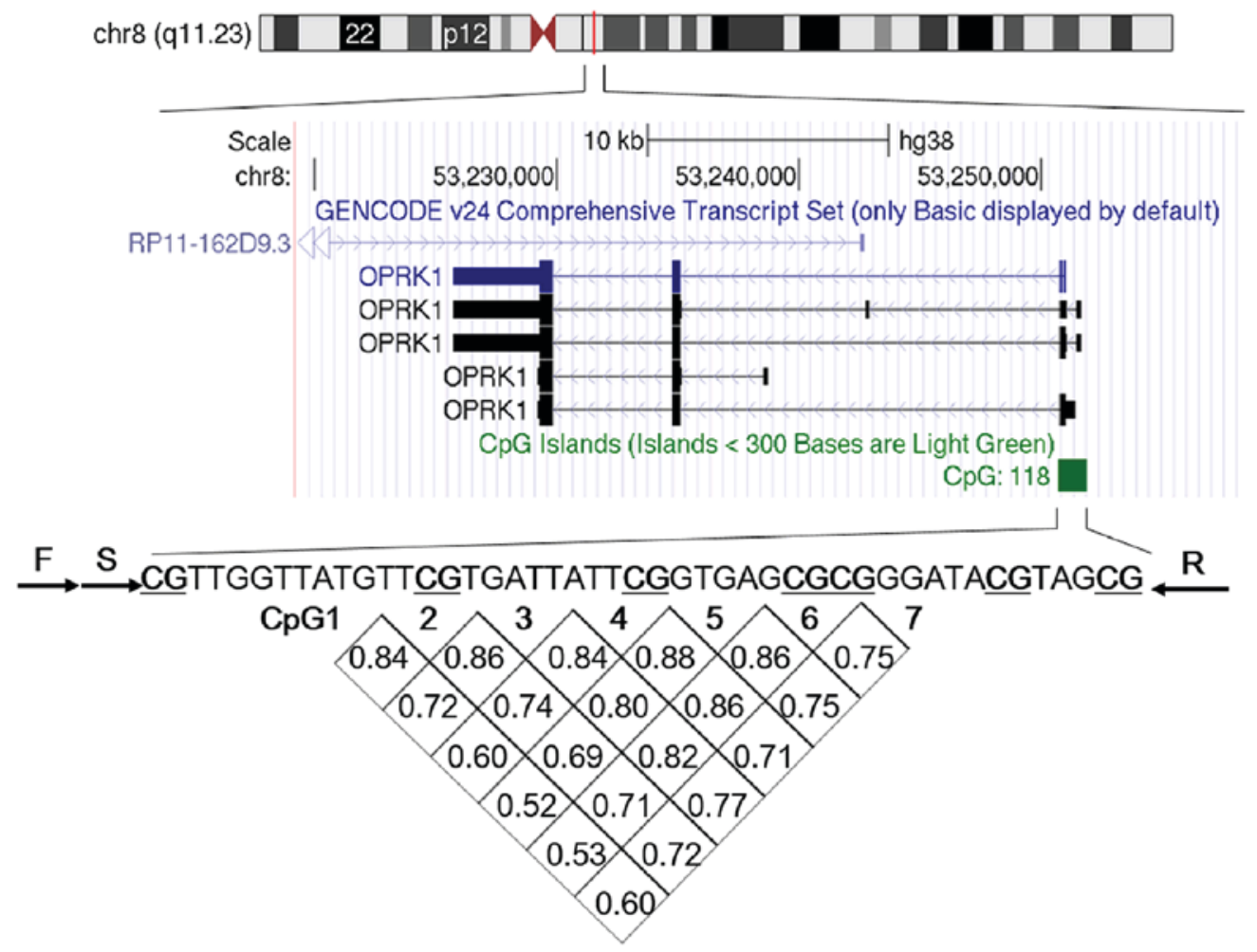

Figure 1. Correlations among seven OPRK1 promoter CpG sites. The target sequence was located in the CpG islands region (light green) of the OPRK1 promoter. The F, R and S primer sequences are provided in the materials and methods section. The numbers in the lattice represent the correlation (correlation coefficient, r) between any two CpG sites. For all P<0.001 and therefore considered to be significant. OPRK1, 11 opioid receptor; CpG, 5'-C-phosphate-G-3'; $\mathrm{F}$, forward; R, reverse; $\mathrm{S}$, sequencing.

Therefore, the average level of CpG1-7 methylation was used for subsequent analyses in the present study.

DNA methylation analysis of the different groups. As depicted in Table I and Fig. 2A, OPRK1 promoter methylation was significantly increased in addicts compared with control subjects, and this was also confirmed in subgroup association tests based on gender (total, $\mathrm{P}=2.43 \times 10^{-4}$; male, $\mathrm{P}=0.004$; female, $\mathrm{P}=0.018)$. Furthermore, increased levels of methylation were observed in the heroin and METH groups when compared with controls (heroin, $\mathrm{P}=0.003$; $\mathrm{METH}, \mathrm{P}=0.001$; Table I and Fig. 2B and C). Similar trends were observed in the subgroup comparisons based on gender in each drug group (for heroin: male, $\mathrm{P}=0.016$ and female, $\mathrm{P}=0.085$; for METH: male, $\mathrm{P}=0.033$ and female, $\mathrm{P}=0.034$; Table I and Fig. $2 \mathrm{~B}$ and $\mathrm{C}$ ). The non-significant association between OPRK1 methylation and heroin addiction in females may be due to a small sample size $(n=30)$. OPRK1 promoter methylation did not differ significantly between heroin and METH addicts, which was confirmed in gender subgroup comparisons (all $\mathrm{P}>0.5$; Table I and Fig. 2D).

Correlation analysis between DNA methylation and phenotypic indices in males. Correlation tests between OPRK1 promoter methylation and phenotypic indices in male subjects were also performed in the present study. The length and frequency of drug use were selected as relevant factors in assessing the situation of addicts. The results indicated that OPRK1 promoter methylation was significantly associated with the length and frequency of drug use in male heroin addicts (length: $\mathrm{r}=0.661, \mathrm{P}=0.007$; frequency: $\mathrm{r}=-0.684$, $\mathrm{P}=0.005$; Fig. 3). No significant association was observed between the phenotypes, including length, frequency and OPRK1 methylation in METH addicts in addition to total addicts ( $\mathrm{P}>0.05$; Fig. 3 ).

Functional analysis of target fragment. Furthermore, a subsequent luciferase reporter gene assay demonstrated that both two OPRK1 promoter fragments (OPRK1 L and OPRK1 S) significantly enhanced luciferase gene activity when compared with a control construct (OPRK1 L vs. OPRK1 S, fold change $=0.86$, $\mathrm{P}=0.013$; OPRK1 L vs. control, fold change $=32.19, \mathrm{P}=1.30 \mathrm{E}-5$; OPRK1 S vs. control, fold change=37.53, P=1.00E-4; Fig. 4).

\section{Discussion}

To elucidate the underlying molecular mechanism of OPRK1 in drug addiction, OPRK1 promoter methylation was compared between drug addicts and controls. The results of the present study demonstrated that OPRK1 promoter methylation was significantly higher in addicts than in control subjects. Significant correlations are also identified between OPRK1 promoter methylation and phenotypic indices (length and frequency of drug use) in male heroin addicts. In addition, two OPRK1 promoter fragments (OPRK1 L and OPRK1 S) were able to regulate gene expression.

Heroin is converted back into morphine after it enters the brain (26). Morphine binds to opioid receptors expressed on the surface of cells, which are particularly involved in the perception of pain and reward mechanisms (27). In the brain, 
Table I. Comparisons of OPRK1 promoter methylation levels among different groups.

\begin{tabular}{|c|c|c|c|c|c|c|c|c|}
\hline \multirow[b]{2}{*}{ Groups } & \multicolumn{8}{|c|}{ P-value } \\
\hline & CpG1 & CpG2 & CpG3 & CpG4 & CpG5 & CpG6 & CpG7 & Average \\
\hline Cases vs. controls (total) & 0.611 & $0.004^{\mathrm{a}}$ & $0.005^{\mathrm{a}}$ & $1.65 \times 10^{-7^{\mathrm{a}}}$ & $3.04 \times 10^{-5^{\mathrm{a}}}$ & $5.51 \times 10^{-5^{\mathrm{a}}}$ & $0.025^{\mathrm{a}}$ & $2.43 \times 10^{-4^{a}}$ \\
\hline Male & 0.569 & $0.016^{\mathrm{a}}$ & $0.013^{\mathrm{a}}$ & $4.93 \times 10^{-5^{\mathrm{a}}}$ & $0.004^{\mathrm{a}}$ & $0.003^{\mathrm{a}}$ & 0.120 & $0.004^{\mathrm{a}}$ \\
\hline Female & 0.895 & 0.073 & 0.115 & 0.001 & $0.003^{\mathrm{a}}$ & $0.003^{\mathrm{a}}$ & 0.112 & $0.018^{\mathrm{a}}$ \\
\hline Heroin vs. controls (total) & 0.383 & 0.038 & 0.056 & $8.06 \times 10^{-7^{\mathrm{a}}}$ & $0.001^{\mathrm{a}}$ & $0.002^{\mathrm{a}}$ & 0.087 & $0.003^{\mathrm{a}}$ \\
\hline Male & 0.341 & 0.074 & 0.080 & $5.12 \times 10^{-5^{\mathrm{a}}}$ & $0.022^{\mathrm{a}}$ & $0.011^{\mathrm{a}}$ & 0.136 & $0.016^{\mathrm{a}}$ \\
\hline Female & 0.772 & 0.336 & 0.351 & $0.004^{\mathrm{a}}$ & $0.029^{\mathrm{a}}$ & $0.114^{\mathrm{a}}$ & 0.354 & 0.085 \\
\hline METH vs. controls (total) & 0.966 & $0.004^{\mathrm{a}}$ & $0.005^{\mathrm{a}}$ & $2.32 \times 10^{-4^{\mathrm{a}}}$ & $1.10 \times 10^{-4^{\mathrm{a}}}$ & $6.59 \times 10^{-5^{\mathrm{a}}}$ & $0.039^{\mathrm{a}}$ & $0.001^{\mathrm{a}}$ \\
\hline Male & 0.959 & $0.040^{\mathrm{a}}$ & $0.034^{\mathrm{a}}$ & $0.006^{\mathrm{a}}$ & $0.015^{\mathrm{a}}$ & $0.034^{\mathrm{a}}$ & 0.278 & $0.033^{\mathrm{a}}$ \\
\hline Female & 0.944 & $0.047^{\mathrm{a}}$ & 0.102 & $0.009^{\mathrm{a}}$ & 0.003 & $0.005^{\mathrm{a}}$ & 0.070 & $0.034^{\mathrm{a}}$ \\
\hline Heroin vs. METH (total) & 0.404 & 0.545 & 0.429 & 0.704 & 0.506 & 0.597 & 0.679 & 0.695 \\
\hline Male & 0.373 & 0.832 & 0.706 & 0.173 & 0.919 & 0.695 & 0.834 & 0.750 \\
\hline Female & 0.739 & 0.569 & 0.498 & 0.654 & 0.478 & 0.440 & 0.478 & 0.531 \\
\hline
\end{tabular}

aP<0.05. METH, methamphetamine; OPRK1, $\kappa 1$ opioid receptor; CpG, 5'-C-phosphate-G-3'.
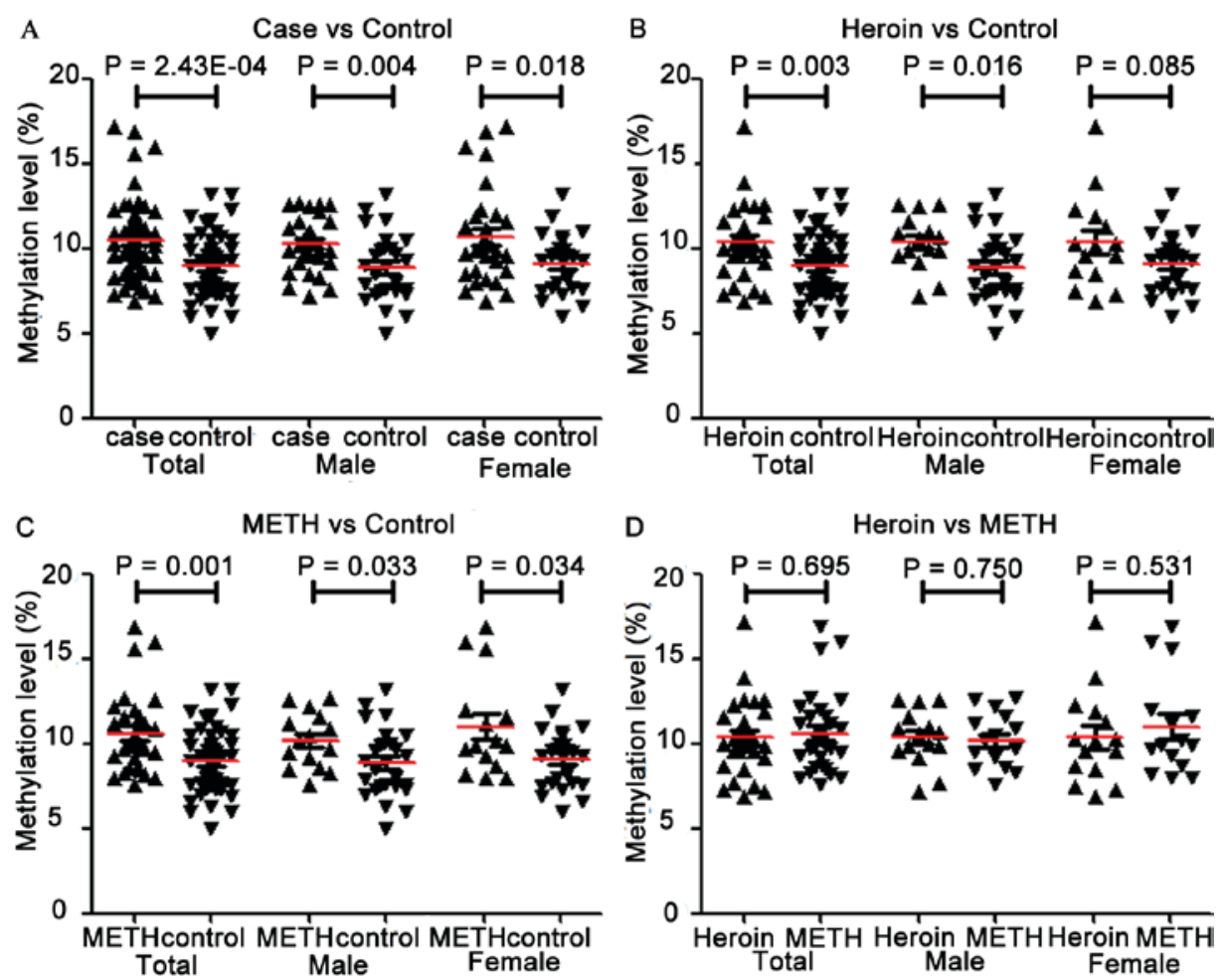

Figure 2. Levels of OPRK1 promoter methylation among different groups: (A) Case vs. Control; (B) Heroin vs. Control; (C) METH vs. Control; (D) Heroin vs. METH. OPRK1, 11 opioid receptor; METH, methamphetamine.

morphine binds to $\mu$ opioid receptors, resulting in euphoric, analgesic and anxiolytic effects (26). OPRK1 is critical in drug addiction, and OPRK1 agonists have inhibitory effects on addictions to alcohol, cocaine and opiate (28). Furthermore, several genetic variants of OPRK1 have been associated with heroin addiction $(8,29,30)$. Previous studies have indicated that heritable factors may be important in addictive behavior $(8,31)$, and suggest that higher levels of OPRK1 promoter methylation may be associated with heroin addiction. The results of the present study indicate that OPRK1 promoter methylation affects the propensity of individuals to exhibit addictive behaviors.

OPRK1 may influence the stress-induced reinstatement of cocaine-seeking $(31,32)$. In a previous study, OPRK1 agonist administration was effective in decreasing cocaine-seeking and self-administration (33). The influence of OPRK1 in drug addiction may principally be due a marked increase in OPRK1 expression in the nucleus accumbens, which is considered to 


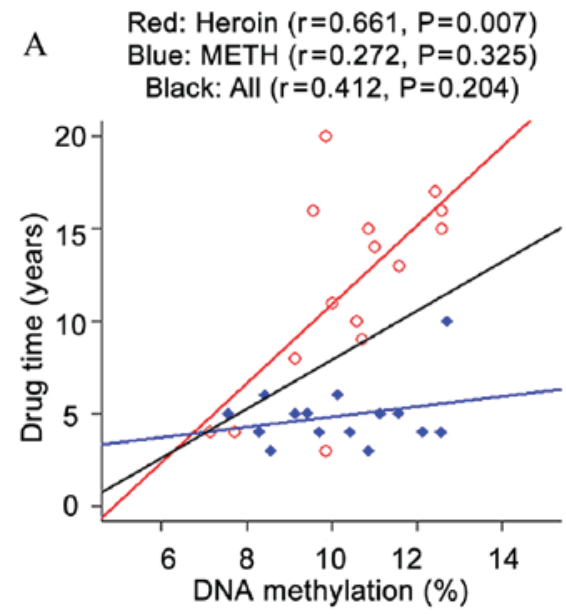

B

Black: All $(r=-0.214, P=0.256)$
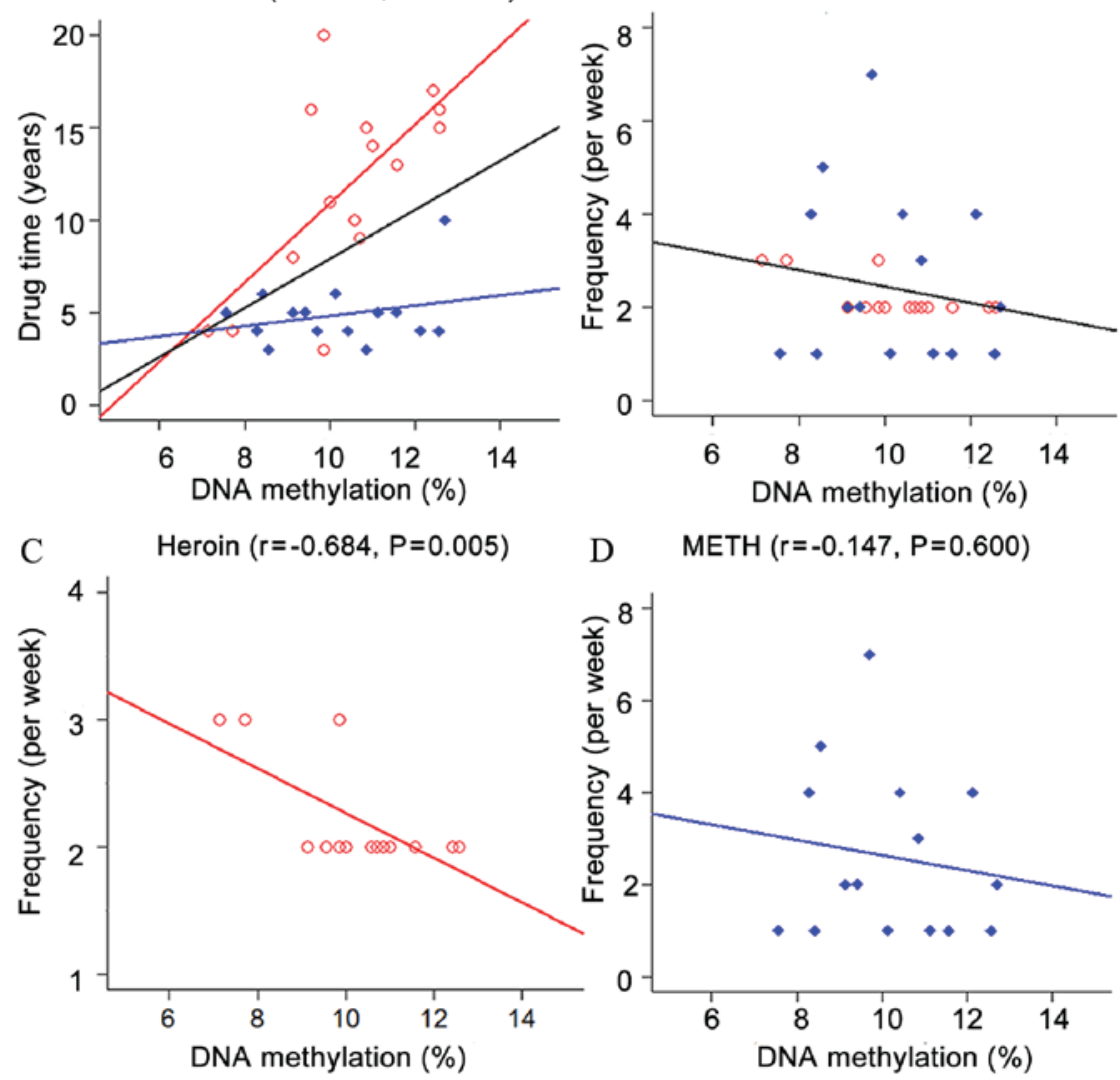

D $\operatorname{METH}(r=-0.147, P=0.600)$

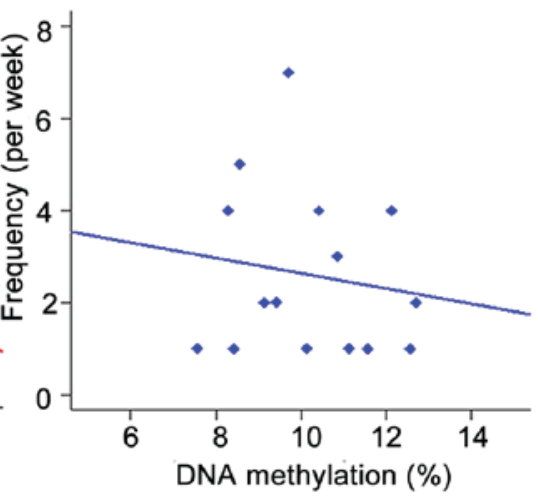

Figure 3. Correlations between OPRK1 promoter methylation and phenotypic indices in male addicts. (A) Associations between drug time and DNA methylation in different populations. (B-D) Association between frequency of drug use and DNA methylation in (B) total, (C) heroin and (D) METH addicts. OPRK1, $\kappa 1$ opioid receptor; METH, methamphetamine.

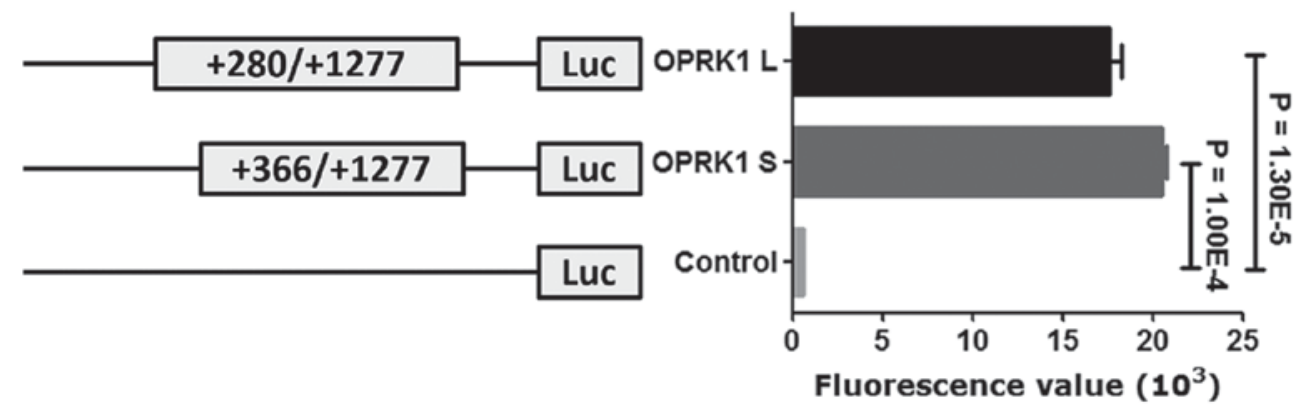

Figure 4. Luc reporter gene assay of OPRK1 promoter fragments. The locations of OPRK1 L and OPRK1 S are shown on the left. The OPRK1 L fragment contained the pyrosequenced sequence, while the OPRK1 S fragment did not. OPRK1, $\kappa 1$ opioid receptor; OPRK1 L, $\kappa 1$ opioid receptor long fragment; OPRK1 S, $\kappa 1$ opioid receptor short fragment; Luc, luciferase.

be most strongly associated with addiction in the brain (34). Numerous other factors have also been associated with heroin addiction, including the method of administration (35) and heroin purity (36). Furthermore, a prolonged duration of heroin usage has been associated with heroin addiction and mortality (37). In the present study, OPRK1 promoter methylation was associated with a longer duration and lower frequency of drug use in male heroin addicts.

METH is a potent central nervous stimulant, and is commonly used as a recreational drug (38). METH may affect the processing and function of monoamines through its effects on the dopamine transporter, monoamine oxidases and vesicular monoamine transporter-2, and inhibition of these molecules by METH has been associated with increased levels of presynaptic cytosolic dopamine and euphoria (39). In the present study, significantly higher OPRK1 promoter methylation was observed in METH addicts when compared with controls, indicating that OPRK1 promoter methylation may serve a pivotal role in METH addiction. In addition, OPRK1 promoter hypermethylation may increase the risk of neurological disease through its regulation of gene expression (25). The present in vitro assay verified that OPRK1 
promoter fragments (including OPRK1 S and OPRK1 L) were able to regulate gene expression. OPRK1 $\mathrm{S}$ exhibits a greater efficacy, compared with OPRK1 L, which indicates that the target fragment may repress the expression of the backward gene. Further functional experiments are required to elucidate the detailed mechanism that controls this expression.

However, the present study had several limitations. Firstly, the sample size was relatively small, which may have affected the outcomes of data analysis, particularly regarding the subgroup analyses. Secondly, the POMS records of female addicts were not available, and thus correlations between OPRK1 methylation and the length and frequency of drug use require further investigation in female addicts. Finally, the present study only assessed the DNA methylation of an OPRK1 promoter fragment, which may not be representative of the whole gene.

In conclusion, the present study suggested that OPRK1 promoter hypermethylation was associated with an increased risk of heroin and METH addiction. Furthermore, OPRK1 hypermethylation was associated with a longer duration and lower frequency of drug use in male heroin addicts. Future studies using larger samples and other populations are now required to confirm the observations of the present study.

\section{Acknowledgments}

The present study was supported by the National Key R\&D Program of China (grant no. 2017YFC1310400), the Natural Science Foundation of Zhejiang (grant no. LY18H090008), the Ningbo Natural Science Foundation (grant nos. 2017A610217 and 2017A04), the Nature Science Foundation of China (no. 81371469) and the K.C. Wong Magna Fund of Ningbo University.

\section{References}

1. Yager LM, Garcia AF, Wunsch AM and Ferguson SM: The ins and outs of the striatum: Role in drug addiction. Neuroscience 301: 529-541, 2015.

2. Jones CM, Logan J, Gladden RM and Bohm MK: Vital signs: Demographic and substance use trends among heroin users - United States, 2002-2013. MMWR Morb Mortal Wkly Rep 64: 719-725, 2015.

3. Wang R, Ding Y, Bai H, et al: Illicit heroin and methamphetamine use among methadone maintenance treatment patients in dehong prefecture of Yunnan province, China. PloS one 10: e0133431, 2015.

4. Wang R, Ding Y, Bai H, Duan S, Ye R, Yang Y, Wang J, Tang R, Gao $\mathrm{M}$ and He N: Illicit heroin and methamphetamine use among methadone maintenance treatment patients in dehong prefecture of yunnan province, China. PLoS One 10: e0133431, 2015.

5. Guerrero M, Urbano M, Brown SJ, Cayanan C, Ferguson J, Cameron M, Devi LA, Roberts E and Rosen H: Optimization and characterization of an opioid kappa receptor (OPRK1) antagonist. In: Probe Reports from the NIH Molecular Libraries Program. Bethesda (MD), 2010.

6. Nielsen DA, Yuferov V, Hamon S, Jackson C, Ho A, Ott J and Kreek MJ: Increased OPRM1 DNA methylation in lymphocytes of methadone-maintained former heroin addicts. Neuropsychopharmacology 34: 867-873, 2009.

7. Faisal M, Waseem D, Ismatullah H and Taqi MM: A molecular prospective provides new insights into implication of PDYN and OPRK1 genes in alcohol dependence. Comput Biol Med 53: 250-257, 2014.

8. Wang SC, Tsou HH, Chung RH, Chang YS, Fang CP, Chen CH, Ho IK, Kuo HW, Liu SC, Shih YH, et al: The association of genetic polymorphisms in the $\kappa$-opioid receptor 1 gene with body weight, alcohol use, and withdrawal symptoms in patients with methadone maintenance. J Clin Psychopharmacol 34: 205-211, 2014.
9. Jablonka E: Epigenetic variations in heredity and evolution. Clin Pharmacol Ther 92: 683-688, 2012.

10. Smith ZD and Meissner A: DNA methylation: Roles in mammalian development. Nat Rev Genet 14: 204-220, 2013.

11. Jeltsch A and Jurkowska RZ: New concepts in DNA methylation. Trends Biochem Sci 39: 310-318, 2014.

12. Branco MR, Ficz G and Reik W: Uncovering the role of 5-hydroxymethylcytosine in the epigenome. Nat Rev Genet 13: 7-13, 2011.

13. Kinney SR and Pradhan S: Regulation of expression and activity of DNA (cytosine-5) methyltransferases in mammalian cells. Prog Mol Biol Transl Sci 101: 311-333, 2011.

14. Cadet JL, Brannock C, Jayanthi S and Krasnova IN: Transcriptional and epigenetic substrates of methamphetamine addiction and withdrawal: Evidence from a long-access self-administration model in the rat. Mol Neurobiol 51: 696-717, 2015.

15. Jayanthi S, McCoy MT, Chen B, Britt JP, Kourrich S, Yau HJ, Ladenheim B, Krasnova IN, Bonci A and Cadet JL: Methamphetamine downregulates striatal glutamate receptors via diverse epigenetic mechanisms. Biol Psychiatry 76: 47-56, 2014.

16. Krasnova IN, Chiflikyan M, Justinova Z, McCoy MT, Ladenheim B, Jayanthi S, Quintero C, Brannock C, Barnes C, Adair JE, et al: CREB phosphorylation regulates striatal transcriptional responses in the self-administration model of methamphetamine addiction in the rat. Neurobiol Dis 58: 132-143, 2013.

17. Robison AJ and Nestler EJ: Transcriptional and epigenetic mechanisms of addiction. Nat Rev Neurosci 12: 623-637, 2011.

18. McQuown SC and Wood MA: Epigenetic regulation in substance use disorders. Curr Psychiatry Rep 12: 145-153, 2010.

19. Xu X, Ji H, Liu G, Wang Q, Liu H, Shen W, Li L, Xie X, Zhou W and Duan S: A significant association between BDNF promoter methylation and the risk of drug addiction. Gene 584: 54-59, 2016.

20. American Psychiatric Association: Diagnostic and Statistical Manual of Mental Disorders. 4th edition. American Psychiatric Association, Washington, DC, 1994.

21. Shen W, Liu Y, Li L, Zhang Y and Zhou W: Negative moods correlate with craving in female methamphetamine users enrolled in compulsory detoxification. Subst Abuse Treat Prev Policy 7: 44, 2012.

22. Kreutz M, Hochstein N, Kaiser J, Narz F and Peist R: Pyrosequencing: Powerful and quantitative sequencing technology. Curr Protoc Mol Biol 104: Unit 7.15, 2013.

23. Chang L, Wang Y, Ji H, Dai D, Xu X, Jiang D, Hong Q, Ye H, Zhang $\mathrm{X}, \mathrm{Zhou} \mathrm{X}$, et al: Elevation of peripheral BDNF promoter methylation links to the risk of Alzheimer's disease. PLoS One 9: e110773, 2014.

24. Edenberg HJ, Wang J, Tian H, Pochareddy S, Xuei X, Wetherill L, Goate A, Hinrichs T, Kuperman S, Nurnberger JI Jr, et al: A regulatory variation in OPRK1, the gene encoding the kappa-opioid receptor, is associated with alcohol dependence. Hum Mol Genet 17: 1783-1789, 2008.

25. Ji H, Wang Y, Liu G, Xu X, Dai D, Chen Z, Zhou D, Zhou X, Han L, Li Y, et al: OPRK1 promoter hypermethylation increases the risk of Alzheimer's disease. Neurosci Lett 606: 24-29, 2015.

26. Gharagozlou P, Hashemi E, DeLorey TM, Clark JD and Lameh J: Pharmacological profiles of opioid ligands at kappa opioid receptors. BMC Pharmacol 6: 3, 2006.

27. Klous MG, Van den Brink W, Van Ree JM and Beijnen JH: Development of pharmaceutical heroin preparations for medical co-prescription to opioid dependent patients. Drug Alcohol Depend 80: 283-295, 2005.

28. Bruchas MR, Xu M and Chavkin C: Repeated swim stress induces kappa opioid-mediated activation of extracellular signal-regulated kinase 1/2. Neuroreport 19: 1417-1422, 2008.

29. Wen S, Wang C, Berg A, Li Y, Chang MM, Fillingim RB, Wallace MR, Staud R, Kaplan L and Wu R: Modeling genetic imprinting effects of DNA sequences with multilocus polymorphism data. Algorithms Mol Biol 4: 11, 2009.

30. Levran O, Londono D, O'Hara K, Nielsen DA, Peles E, Rotrosen J, Casadonte P, Linzy S, Randesi M, Ott J, et al: Genetic susceptibility to heroin addiction: A candidate gene association study. Genes Brain Behav 7: 720-729, 2008.

31. Gerra G, Leonardi C, Cortese E, D'Amore A, Lucchini A, Strepparola G, Serio G, Farina G, Magnelli F, Zaimovic A, et al: Human kappa opioid receptor gene (OPRK1) polymorphism is associated with opiate addiction. Am J Med Genet B Neuropsychiatr Genet 144B: 771-775, 2007. 
32. Black SM, Ellard S, Meehan RR, Parry JM, Adesnik M, Beggs JD and Wolf CR: The expression of cytochrome P450IIB1 in Saccharomyces cerevisiae results in an increased mutation frequency when exposed to cyclophosphamide. Carcinogenesis 10: 2139-2143, 1989.

33. Schenk S, Partridge B and Shippenberg TS: U69593, a kappa-opioid agonist, decreases cocaine self-administration and decreases cocaine-produced drug-seeking. Psychopharmacology (Berl) 144: 339-346, 1999.

34. Mash DC and Staley JK: D3 dopamine and kappa opioid receptor alterations in human brain of cocaine-overdose victims. Ann N Y Acad Sci 877: 507-522, 1999.

35. Gossop M, Griffiths P, Powis B, Williamson S and Strang J: Frequency of non-fatal heroin overdose: Survey of heroin users recruited in non-clinical settings. BMJ 313: 402, 1996.
36. Darke S, Ross J, Zador D and Sunjic S: Heroin-related deaths in New South Wales, Australia, 1992-1996. Drug Alcohol Depend 60: 141-150, 2000.

37. Darke S and Zador D: Fatal heroin 'overdose': A review. Addiction 91: 1765-1772, 1996.

38. Scott JC, Woods SP, Matt GE, Meyer RA, Heaton RK, Atkinson JH and Grant I: Neurocognitive effects of methamphetamine: A critical review and meta-analysis. Neuropsychol Rev 17: 275-297, 2007.

39. Cruickshank CC and Dyer KR: A review of the clinical pharmacology of methamphetamine. Addiction 104: 1085-1099, 2009.

(i) $($ ) This work is licensed under a Creative Commons Attribution-NonCommercial-NoDerivatives 4.0 International (CC BY-NC-ND 4.0) License. 